Bond University

Research Repository

\title{
A biomechanical analysis of the heavy sprint-style sled pull and comparison with the back squat
}

Winwood, Paul W.; Cronin, John B.; Brown, Scott R.; Keogh, Justin W L

Published in:

International Journal of Sports Science and Coaching

DOI:

10.1260/1747-9541.10.5.851

Licence:

Other

Link to output in Bond University research repository.

Recommended citation(APA):

Winwood, P. W., Cronin, J. B., Brown, S. R., \& Keogh, J. W. L. (2015). A biomechanical analysis of the heavy sprint-style sled pull and comparison with the back squat. International Journal of Sports Science and Coaching, 10(5), 851-868. https://doi.org/10.1260/1747-9541.10.5.851

\section{General rights}

Copyright and moral rights for the publications made accessible in the public portal are retained by the authors and/or other copyright owners and it is a condition of accessing publications that users recognise and abide by the legal requirements associated with these rights.

For more information, or if you believe that this document breaches copyright, please contact the Bond University research repository coordinator. 


\section{A BIOMECHANICAL ANALYSIS OF THE HEAVY SPRINT-STYLE SLED PULL AND COMPARISON WITH THE BACK SQUAT}

"This manuscript contains material that is original and not previously published in text or on the Internet, nor is it being considered elsewhere until a decision is made as to its acceptability by the International Journal of Sports Science and Coaching"

Paul W Winwood

Bay of Plenty Polytechnic

Windermere Drive

Tauranga 3143

Ph: 08002677659 x6125

Email: paul.winwood@ boppoly.ac.nz 
A BIOMECHANICAL ANALYSIS OF THE HEAVY SPRINT-STYLE SLED PULL AND COMPARISON WITH THE BACK SQUAT

Paul W. Winwood ${ }^{1,2}$., John B. Cronin, ${ }^{1,3}$., Scott R. Brown, ${ }^{1}$., and Justin W. L. Keogh, ${ }^{1,4,5}$.

${ }^{1}$ Sport Performance Research Institute New Zealand, School of Sport and Recreation, AUT University, Auckland, New Zealand

${ }^{2}$ Bay of Plenty Polytechnic, School of Applied Science, Tauranga, New Zealand

${ }^{3}$ Edith Cowan University, School of Exercise, Biomedical and Health Sciences, Perth, Australia

${ }^{4}$ Faculty of Health Sciences and Medicine, Bond University, Gold Coast, Australia

${ }^{5}$ University of the Sunshine Coast, Cluster for Health Improvement, Faculty of Science, Health, Education and Engineering, Queensland, Australia

Paul Winwood, Ph 08002677659 x6125 Email paul.winwood@boppoly.ac.nz 


\begin{abstract}
This study compared the biomechanical characteristics of the heavy sprint-style sled pull and squat. Six experienced male strongman athletes performed sled pulls and squats at $70 \%$ of their 1RM squat. Significant kinematic and kinetic differences were observed between the sled pull start and squat at the start of the concentric phase and at maximum knee extension. The first stride of the heavy sled pull demonstrated significantly $(\mathrm{p}<0.05)$ lower stride lengths and average velocities and a higher mean ratio of force than the stride at $2-3 \mathrm{~m}$. The force orientation and magnitude associated with the heavy sprint-style sled pull demonstrates that the heavy sled pull may be an effective conditioning stimulus to generate superior anteriorpropulsive forces compared to vertically orientated exercises such as the squat with the same given load. Such adaptations may be beneficial in sports where higher levels of sprint momentum are needed to make and break tackles.
\end{abstract}

Keywords: Biomechanics, kinematics; kinetics; strongman; resistance training 


\section{INTRODUCTION}

Strongman is a sport similar to weightlifting, bodybuilding and powerlifting in which weight training is the primary form of training [1]. The heavy sprint-style sled pull is a strongman competition event (similar to the truck pull) in which participants wear a chest-mounted harness which is tethered to the weighted sled positioned behind the athlete. Successful performance in the heavy sprint-style sled pull event is based on the fastest times to complete the event. Recently, the heavy sprint-style sled pull has gained attention as a proposed form of training that may be beneficial for athletes whose sports require high levels of horizontal total momentum (i.e. body mass $\mathrm{x}$ velocity $\left(\mathrm{kg} \mathrm{ms}^{-1}\right)$ ), such as track and field athletes and athletes of the rugby codes (i.e. rugby union, rugby league, and National Football League) [2-5].

The use of resisted sprinting training methods (such as the heavy sprint-style sled pull) are believed to increase power and strength through more muscle fibre recruitment and neural activation which consequently lead to an increase in stride length [6]. Keogh and colleagues [3] found that the heavy sprint-style sled pull shared many kinematic similarities to acceleration phase of sprinting, although the sled pull had somewhat smaller step lengths and step rates, longer ground contact times and a more horizontal trunk. Six resistance-trained athletes performed three $25-\mathrm{m}$ sets with a load of $171.2 \mathrm{~kg}$ with 3 minutes rest between sets. Within subject analyses demonstrated that the fastest trials were often characterised by significantly greater step lengths, step rates and shorter ground contact times than the slower trials. Keogh et al. [3] surmised that based on the impulse-momentum relationship, greater anteroposterior force/impulses were produced in the fastest sled pulls. Keogh and colleagues [3] hypothesised that the heavy sprint-style sled pull may help improve acceleration sprinting performance. 
However, the view of Keogh et al. [3] is inconsistent with some other authors who believe that the acute alteration in sprint kinematics observed during resisted sprinting training will not facilitate the practice and refinement of the correct neuromuscular pattern that would occur in non-resisted sprinting [7, 8]. These authors' beliefs appear based on research demonstrating that athletes experience an acute decrement in resisted sprinting speed via a reduction of step length and step rate and increased ground contact time, with these effects becoming more pronounced as the loads exceed $20 \%$ body mass [8-10].

Inspection of resisted sprint training studies highlights that no heavy sprint-style sled pull training studies have utilised loads such as those used by Keogh et al. [3], however researchers have reported that loads of $13 \%$ body mass and sled weights of $33 \mathrm{~kg}$ (43\% of mean participant body mass) are effective at significantly improving $5 \mathrm{~m}[11,12]$ and $10 \mathrm{~m}$ sprint times [11]. Kawamori and colleagues [11] compared the effects of heavier and lighter weighted sled towing on sprint acceleration ability. The study found that after 8-weeks of training twice weekly, the heavier sled $(33.1 \pm 5.9 \mathrm{~kg})$ training group significantly improved both 5 - and 10 -m sprint time $(5.7 \pm 5.7 \%$ and $5.0 \pm 3.5 \%)$, whereas only the 10 -m sprint time was improved significantly by $3.0 \pm 3.5 \%$ in the lighter sled $(10.8 \pm 2.3 \mathrm{~kg})$ group. An interesting finding in the study of Kawamori et al. [11] was that sprint speed increased as a result of improvements in step frequency and may have been attributed to decreased vertical impulse production. Kawamori and colleagues [11] therefore hypothesised that weighted sled towing with heavier loads improves sprint acceleration performance by teaching athletes to produce larger horizontal or resultant GRF impulse.

While the studies of Keogh et al. [3] and Kawamori et al. [11] were both successful in obtaining some kinematic determinants of performance and training adaptations associated 
with heavier sled towing loads, there is a lack of knowledge of biomechanical characteristics (e.g. magnitude and direction of force application and kinematic differences between early and latter sled pull strides), associated with the heavy sprint-style sled pull as compared to traditional exercises such as the squat. Since heavy sled pulls are the most commonly used strongman-type implement used by coaches in strength and conditioning practice [5], it is important for coaches to have data on the kinematics and kinetics of this event to understand the potential stresses this event places on the body. Such data would give practitioners a greater understanding of the applications and likely chronic adaptations to this form of training. Therefore the purpose of this study was to examine the kinetic and kinematic characteristics of the heavy sprint-style sled pull. The heavy sprint-style sled pull was analysed in three phases: 1) the initial start (bilateral start to maximum knee extension); 2) first stride; and 3) stride at $2-3 \mathrm{~m}$. The stride pattern (phases 2 and 3) were analysed to help give insight into changes in kinematics, force application/direction and the influence of static verus sliding friction during early acceleration.

The start of the heavy sled pull (from the bilateral start of the concentric phase to the maximum point of knee extension) was analysed and compared with the squat, as the movement patterns between these two exercises are comparable during this phase. Such data will give insight into the similarities and differences in kinematics and kinetics (such as direction of force application) associated with these exercises. Such an analysis is analogous to a recently published paper by Winwood and colleagues [13] comparing a strongman event referred to as the farmers walk to a similar traditional exercise, the deadlift. The study compared similar phases of the farmers walk with traditional exercises, and analysed the farmers lift with the deadlift and the farmers walk with unloaded walk [13]. These types of studies may also help equate loading and time under tension in future training studies wishing 
to compare exercises such as heavy sprint-style sled pull versus the squat on aspects of muscular function and performance. It was hypothesised that the mean ratio of forces would be higher in the heavy sled pull's first stride compared to the stride at $2-3 \mathrm{~m}$ and the start of the heavy sled pull (to maximum knee extension) would show significantly greater anteroposterior and lower vertical forces compared to the squat.

\section{METHODS}

\section{EXPERIMENTAL APPROACH TO THE PROBLEM}

A cross-sectional descriptive design was used to quantify the kinematics and kinetics of heavy sprint-style sled pull and the squat. The participants were well-trained strongman athletes with extensive experience performing the traditional and strongman lifts. Data were collected for each participant over two sessions separated by one week. Session 1 was performed in the strength and conditioning laboratory and involved 1-repetition maximum $(1 \mathrm{RM})$ testing in the squat. Session 2 was performed in the biomechanics laboratory where participants performed repetitions in the squat and heavy sled pull (respectively) on force plates using loads equal to $70 \%$ of the squat $1 \mathrm{RM}$ load for both exercises. Kinematics and kinetics were recorded during the second session. The sled pull was analysed in three phases; 1) the initial start (bilateral start of the concentric phase to maximum knee extension); 2) first stride; and 3) stride at $2-3 \mathrm{~m}$. Only the initial start of the heavy sled pull (where feet were together) was compared with the squat, given the biomechanical similarities between the two exercises in this phase.

\section{PARTICIPANTS}

Six male strongman athletes (four national and two local level athletes) volunteered to participate in this study (mean \pm SD: age $24.0 \pm 3.9 \mathrm{yr}$; stature $181.6 \pm 9.4 \mathrm{~cm}$; body mass 
$112.9 \pm 28.9 \mathrm{~kg}$ ). A summary of the participants' descriptive statistics is presented in Table 1 . All participants regularly performed 1RM testing as part of their training and had an extensive strength training background; including experience with the squat and heavy sprint-style sled pull. The study was conducted 2 weeks before a regional strongman competition where the majority of athletes were at the end of a training cycle aimed at improving their previous competition performance. To be eligible to participate in this study the strongman athletes had to have competed in at least one strongman competition and be injury free. Prior to participation, all aspects of the research were verbally explained to each athlete, written informed consent was obtained and a coded number was assigned to each athlete to ensure the data remained anonymous. Full ethical approval for human subject research was granted for all procedures used in this study by the Auckland University of Technology Ethics Committee $(12 / 311)$.

\section{ONE-REPETITION MAXIMUM TESTING}

No supportive aids beyond the use of a weightlifting belt were permitted during the test. The warm up, loading increments and rest periods used were according to previously established protocols [14]. Maximum strength was assessed by a 1RM performed with a free-weight Olympic-style barbell. Squat 1RM was assessed using the methods outlined by Baker [15]. Participants performed the low-bar back squat (powerlifting squat) as this squat is typically utilised in training and competition by strongman athletes.

\section{SQUAT AND SLED PULL TESTING}

Before performing the lifts, participants engaged in a self-selected total body dynamic warmup similar to their specific weight training and competition warm-up procedures. Generally this began with 2 light sets of each lift (e.g., <40\%1RM) for 6-10 repetitions. All the 
participants then performed testing loads of each exercise before any data collection. Once suitably prepared, the participants performed a trial of the exercise to commence with a load of $70 \% 1 \mathrm{RM}$. Loading for the sled pull, was determined by the athletes' $70 \% 1 \mathrm{RM}$ squat. Athletes' were asked to perform the squat and heavy sprint-style sled pull as explosively as possible.

For the heavy sprint-style sled pull participants were instructed to start in a four-point power position and accelerate the heavy sled forward over a linoleum-coated floor as quickly as possible using powerful triple extension of the lower body. Carpet was attached to the bottom of the sled so that it could be dragged across the linoleum floor surface without causing damage to the floor (see Figure 1). Each participant performed two trials starting on the force plates and two trials starting $2 \mathrm{~m}$ behind the force plates.

Insert Figure 1 about here.

The lifts were performed in a non-randomised order involving the squat then the heavy sled pull. This order was necessary as the heavy sprint-style sled pull was deemed to be the most metabolic demanding exercise. Participants performed three consecutive squat repetitions and then performed two sled pull trials on the force plate and two sled pull trials from $2 \mathrm{~m}$ behind the force plate. The first phase of the sled pull was chosen to obtain kinetic data of; a) the start of the movement to maximum knee extension and b) the first stride of the sled pull where the athlete who starts on the force plate has to overcome static friction of the sled. The second starting position of $2 \mathrm{~m}$ behind the force plate was selected so to provide data on an early dynamic phase of the sled pull (stride at $2-3 \mathrm{~m}$ ) in which the athlete has to overcome the sliding friction of the sled. Participants were allocated a rest period of 5-minutes between the 
sled pull trials. Consistent verbal encouragement was provided during testing sessions with the athletes' frequently reminded to perform the exercises as fast as possible. The participant's best squats and sled pulls (determined by the participants) were used for analysis. If participants identified no differences in technical proficiency between trials, the trial with the highest resultant force was used for analysis. The sled (Strongman pulling sled, $11.5 \mathrm{~kg}$, length $600 \mathrm{~mm}$, width $400 \mathrm{~mm}$ ) used in this study were purchased from Getstrength (Auckland, New Zealand). Shoes worn by participants during testing were those that were typically worn in their strongman training.

\section{INSTRUMENTATION}

Twelve markers were bilaterally placed over the base of the third metatarsal, lateral malleoli, lateral femoral condyles, greater trochanter, anterior superior iliac spine, and superior boarder of the acromion process. Two Sony (HDR - CX 190E) cameras (Tokyo, Japan) were used to track the coordinates of reflective markers, adhered to the body, during the various trials at a sample rate of $60 \mathrm{~Hz}$. A Bertec force plate (Model AM6501, Bertec Corp., Columbus, OH, USA) was used to collect synchronized ground reaction forces at $1000 \mathrm{~Hz}$. A diagrammatic representation of the 2 cameras and force platform set-up is presented in Figure 2. Vicon Nexus (Version 1.8.1, Vicon Inc., Denver, CO, USA) was used to process the ground reaction force data. Ground reaction force data were filtered using a fourth order low-pass digital Butterworth filter with a cut-off frequency of $6 \mathrm{~Hz}$.

Insert Figure 2 about here.

\section{DATA ANALYSIS}

Two linear kinematic (average velocity and stride length), three temporal (stride rate, ground contact time and swing time) and four segment/joint angle (trunk, hip, knee and ankle) 
variables were calculated. Squat and the sled pull start angles were recorded at the start of concentric phase (SC) (first frame before upward or forward movement, respectively), and at maximal knee extension - (MKE) (See Figure 3). These positions were chosen as they were similar positions that could be compared between the two exercises. Sled pull stride angles were recorded at foot strike (first point of ground contact) and toe-off (first point of foot leaving the ground). For the purposes of this study, sled pull strides were analysed in positions (i.e. first stride and stride at 2 - $3 \mathrm{~m}$ ). The internal hip, knee and ankle angles (joint angles) were measured along with the trunk angle in relation to the vertical axis (see Figure 4). A general measure of the range of motion (ROM) of these joint/segments was obtained by subtracting the angle at toe off from that at foot strike, and start of concentric phase from the point of maximal knee flexion. 2D kinematics for the trunk, hip, knee and ankle angles were calculated for the right side and were analysed in Kinovea (version 0.8.15, www.kinovea.org). Intra-rater reliability of Kinovea for determining similar lower body joint angles has been shown to be high (ICC $=0.96-0.99$; typical error $1-2^{\circ}$ ) [16]. Linear kinematics and temporal values were analysed in Vicon Nexus.

Insert Figure 3 about here

Force data was normalised for time using ensemble averaging in Microsoft Excel 2007 and presented as peak and mean values. Vertical forces were described as acting in the $\mathrm{Z}$ direction, with upwards directed forces being positive. Forces in the $\mathrm{X}$ and $\mathrm{Y}$ axis were calculated as medial (positive) and lateral (negative), and anterior (propulsive ${ }^{+}$) and posterior (braking-), respectively. Sum of mean forces in the $\mathrm{X}$ and $\mathrm{Y}$ axes were calculated as the total mean (e.g. $\mathrm{X}=$ medial + lateral forces). A definition for all the kinematic and temporal variables (adapted from Keogh et al. [17]) is given below. 
Average Velocity $\left(\mathrm{m} \cdot \mathrm{s}^{-1}\right)$ : The total distance from the first foot contact to the next foot contact of the same foot divided by the time taken.

Stride length $(\mathrm{m})$ : Horizontal distance from the first foot contact to the next foot contact of the same foot.

Stride rate $(\mathrm{Hz})$ : The number of strides per second. Calculated as the inverse of the stride time, where stride time is from heel strike to heel strike of the same foot.

Ground contact time (s): Time from foot strike to toe off of the same foot.

Swing time (s): Time from toe off to foot strike of the same foot.

The four joint angles analysed in this study (Figure 4) were defined as follows:

Trunk angle (A): The angle subtended from shoulder and hip to the vertical axis, with smaller values indicating greater trunk extension.

Hip angle (B): The internal angle subtended from the shoulder, hip and and knee markers, with increasing values indicating greater hip extension.

Knee angle $(\mathrm{C})$ : The internal angle subtended from the hip, knee and ankle markers, with $180^{\circ}$ indicating full knee extension.

Ankle angle (D): The internal angle subtended from the knee, ankle and toe, with increasing values indicating plantarflexion.

Insert Figure 4 about here

In addition to examining the magnitude of force application in all three axes, we also investigated the direction of force application by calculating the mean ratio of forces applied onto the ground $[18,19]$. The ratio $(\%)$ was calculated as the mean ratio of horizontal force

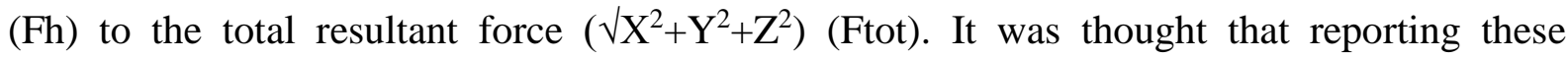
variables would give coaches a better idea of how horizontally oriented the heavy sprint-style sled pull is, and allow indirect comparison relative to previous research on sprint acceleration, and lighter sled towing methods $[18,19]$. 


\section{STATISTICAL ANALYSIS}

Means and standard deviations were used as measures of centrality and spread of data. Twotailed paired t-tests were used to determine if any statistical differences existed in kinematics and ground reaction forces between the squat and sled pull (from the start of position of the concentric phase to the maximum knee extension), and the two sled pull stride positions (for the first stride and the stride at $2-3 \mathrm{~m}$ ). Statistical significance was set at $p \leq 0.05$. All analyses were performed using IBM Statistical Package for the Social Sciences (Version 20.0, SPSS for Windows).

\section{RESULTS}

Descriptive characteristics of all strongman athletes are presented in Table 1. On average strongman athletes trained four times a week for $\sim 90$ minutes per session for a total of 6.4 hours of strongman/resistance training per week.

Insert Table 1 about here.

\section{EXERCISE KINEMATICS BETWEEN THE SQUAT AND HEAVY SLED PULL}

Participants demonstrated a greater stance width in the squat $(51.01 \pm 9.98 \mathrm{~cm} ; \mathrm{p}=0.049)$ compared to the start of the heavy sled pull $(40.88 \pm 9.76 \mathrm{~cm})$. As expected, significant differences were observed in trunk angles between the squat and sled pull, with the sled pull trunk angle being significantly more horizontal at the start of concentric phase (SC) and at the point of maximal knee extension - (MKE)) (see Table 2). The squat demonstrated significantly greater knee flexion at SC and greater knee and hip extension at MKE. Hip and knee range of motion (ROM) was greater in the squat (205\% and $280 \%$, respectively) compared to the sled pull. 
Insert Table 2 about here.

EXERCISE KINETICS BETWEEN THE SQUAT AND THE HEAVY SLED PULL (FROM SC TO MKE)

The squat was found to have significantly higher peak and mean vertical forces (both 2 times greater) than the start of the heavy sled pull, whereas the start of the heavy sled pull had significantly higher peak (6 times greater) and mean anterior forces (13 times greater) (see Table 3) than the squat. The sum of Y forces was significantly $(\mathrm{p}<0.001)$ greater in the sled pull compared to the squat. Significant differences $(\mathrm{p}<0.001)$ in the mean ratio of forces were evident between the start of the heavy sled pull and the squat, with the squat demonstrating force in the vertical direction $(\mathrm{RF}=0.2 \pm 0.3 \%)$ as opposed to the greater horizontal force orientation $(\mathrm{RF}=39.3 \pm 5.9 \%)$ associated with the start of the heavy sled pull. Total lift time for one repetition of the squat (including eccentric and concentric phases) was $2.81 \pm 0.50 \mathrm{~s}$.

Insert Table 3 about here.

Pictorial representations of group mean ground reaction force curves (normalised to percentage of mean lift time) for the squat and heavy sprint-style sled pull from SC to MKE are presented in Figure 5. Differences in the shapes of the force time curves in the $\mathrm{Z}$ and $\mathrm{Y}$ axis are clearly evident; however some similarities can be observed in the $\mathrm{X}$ axis.

Insert Figure 5 about here. 


\section{EXERCISE KINEMATICS BETWEEN HEAVY SLED PULL STRIDES}

Significant differences were found between the heavy sled pull first stride and stride at 2 - $3 \mathrm{~m}$ with the first stride demonstrating reduced stride lengths $(1.00 \pm 0.15 \mathrm{~m}$ versus $1.29 \pm 0.17 \mathrm{~m})$

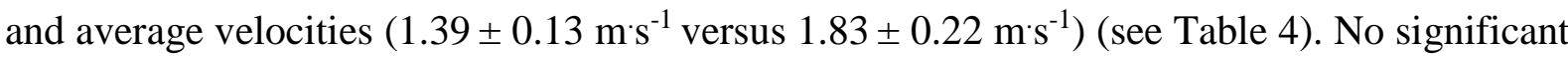
differences were observed for any of the segment or joint angles except for knee angle in which the first stride of the sled pull demonstrated greater knee flexion $\left(103.0 \pm 9.4^{\circ}\right.$ versus $\left.113.8 \pm 5.9^{\circ}\right)$ at foot strike

Insert Table 4 about here.

\section{EXERCISE KINETICS BETWEEN HEAVY SLED PULL STRIDES}

A significantly higher $(\mathrm{p}=0.009)$ mean ratio of force was associated with the first stride of the heavy sled pull $(\mathrm{RF}=37.4 \pm 3.8 \%)$ than the stride at $2-3 \mathrm{~m}(\mathrm{RF}=21.7 \pm 7.1 \%)$. No significant differences between the first and 2 - $3 \mathrm{~m}$ strides were observed for other kinetic variables except for mean of $\mathrm{X}$ and mean of $\mathrm{Y}$ forces, in which the first stride of sled pull demonstrated significantly higher mean anteroposterior forces $(526 \pm 162 \mathrm{~N}$ versus $271 \pm 89$ $\mathrm{N})$ and mean medial forces $(24 \pm 8 \mathrm{~N}$ versus $-5 \pm 22 \mathrm{~N})$ (see Table 5$)$.

Insert Table 5 about here.

Group mean average force-time curves (normalised to percentage of mean lift time) obtained with heavy sled pulling at first stride and stride at $2-3 \mathrm{~m}$ are presented in Figure 6 . Greater fluctuations in the magnitude of forces are clearly observed in the vertical axis in the sled pull stride at $2-3 \mathrm{~m}$.

Insert Figure 6 about here. 


\section{DISCUSSION}

Since the heavy sled pull is the most commonly used strongman implement used by coaches in strength and conditioning practice as a means of performance enhancement [5], it is important to obtain data on the heavy sled pull that can provide insight into its effectiveness as a conditioning stimulus. The aim of this study was to gain a greater understanding of the acute stresses that the heavy sled pull imposes on the system and the likely chronic adaptations to this form of training. To achieve this, the kinetic and kinematic characteristics of the sprint-style heavy sled pull (first stride and stride at $2-3 \mathrm{~m}$ ) were quantified, with the start of the sled pull (start of concentric phase to maximal knee extension) compared with the back squat.

Results of the present study were consistent with the initial hypotheses, whereby the heavy sled pull (from start to MKE) demonstrated significantly greater peak $(810 \pm 174 \mathrm{~N}$ versus $126 \pm 73 \mathrm{~N}$ ) and mean anteroposterior (propulsive) forces $(555 \pm 107 \mathrm{~N}$ versus $43 \pm 22 \mathrm{~N}$ ) than the squat (respectively) and the squat demonstrated significantly greater peak $(3503 \pm$ $1286 \mathrm{~N}$ versus $1736 \pm 463 \mathrm{~N})$ and mean vertical forces $(2579 \pm 648 \mathrm{~N}$ versus $1326 \pm 364 \mathrm{~N})$ than the heavy sled pull (start to MKE) (respectively). Significant differences $(\mathrm{p}<0.001)$ in the mean ratio of forces $(\mathrm{RF})$ were evident with the squat demonstrating that total force was applied vertically $(\mathrm{RF}=0.2 \pm 0.3 \%)$ compared to the more horizontal orientation $(\mathrm{RF}=39.3$ $\pm 5.9 \%$ ) associated with the start of the heavy sprint-style sled pull.

Research has demonstrated that both vertical and propulsive ground reaction force impulses (F x $\Delta t$ ) are important variables that contribute to sprint velocity [20-22]. Producing larger impulse in a vertical direction during ground contacts would result in greater vertical velocity of the centre of mass at take-off which subsequently leads to a longer flight time [20]. 
However, spending an unnecessarily long time in the air may not be desirable, especially in the acceleration phase, because an athlete can only horizontally accelerate their centre of mass when applying a force to the ground. Researchers have suggested that propulsive anteroposterior ground reaction forces may be the greatest contributor to sprint performance during un-resisted sprint starts $[21,23,24]$ and that weighted sled towing with heavier loads can improve sprint acceleration performance by teaching athletes to produce larger horizontal or resultant GRF impulse $[11,25]$. The ground reaction force data from the present study gives insight into the potential training adaptations associated with the squat and heavy sled pull.

The results of this study revealed significant biomechanical differences between the start of the heavy sled pull and squat. Significant differences were observed in absolute trunk angles $\left(38.8 \pm 5.2^{\circ}\right.$ versus $\left.101.4 \pm 5.7^{\circ}\right)$ at the start of the concentric phase. Such a result was expected due to the predominantly horizontal and vertical directional movement patterns associated with the heavy sled pull and squat, respectively. The strongman athletes selected a significantly wider stance width for the squat $(51.0 \pm 10.0 \mathrm{~cm})$ compared to $40.9 \pm 9.8 \mathrm{~cm}$ for the heavy sled pull. The squat stance width in the present study was similar to those reported among powerlifters for traditional stance widths $(48.3 \pm 3.8 \mathrm{~cm})[26]$.

An interesting finding in this study was that at the start of the concentric phase, squat and sled pull relative hip $\left(57.0 \pm 9.7^{\circ}\right.$ versus $\left.65.6 \pm 12.6^{\circ}\right)$ and ankle angles $\left(81.0 \pm 7.3^{\circ}\right.$ versus $76.0 \pm$ $\left.17.3^{\circ}\right)$ were somewhat similar. However greater knee extension $\left(95.8 \pm 18.5^{\circ}\right.$ versus $62.6 \pm$ $6.3^{\circ}$ ) was observed at the start of the sled pull. The greater knee extension seen at the start of the sled pull may provide athletes with a more optimal position to generate propulsive forces based on the muscles being at a more favourable length to take advantage of the length- 
tension relationship. The greater knee flexion angle seen in the squat was attributed to the participants' familiarity with powerlifting competition rules whereby a legal squatting depth requires the hip joint to pass below that of the knee. As a result, greater range of motion was observed in hip $\left(106.0 \pm 9.3^{\circ}\right.$ versus $\left.51.8 \pm 19.0^{\circ}\right)$ and knee joints $\left(104.8 \pm 9.8^{\circ}\right.$ versus $37.4 \pm$ $\left.14.7^{\circ}\right)$ for the squat. Recent research has demonstrated that deep squat $\left(0-120^{\circ}\right.$ of knee flexion) training (with loads of 5-10 RM) resulted in greater increases in front thigh muscle CSA, isometric knee extension strength (at $75^{\circ}$ and $105^{\circ}$ knee extension) and squat jump performance than 12 weeks of shallow squat training (with loads of 5 -10 RM) [27]. The findings of the present study and those of Bloomquist et al. [27] could suggest that the heavy sprint-style sled pull may not be as effective at developing aspects of muscular function and performance that are associated with the full range back squat. Future studies could investigate the training effects of heavy sled pulling on strength, power, speed and body composition measures to give insight into the mechanical and morphological adaptations associated with heavy sled pulling.

The present study sought to provide further insight into the heavy sled pull by providing kinematic and kinetic data of the first stride and stride at $2-3 \mathrm{~m}$. Relatively few significant differences were apparent between the two sled pull phases. The first stride of sled pull was associated with significant shorter stride lengths $(1.00 \pm 0.15 \mathrm{~m}$ versus $1.29 \pm 0.17 \mathrm{~m})$ and slower average velocities $\left(1.39 \pm 0.13 \mathrm{~m} \cdot \mathrm{s}^{-1}\right.$ versus $\left.1.83 \pm 0.22 \mathrm{~m}^{-1}\right)$ than the stride at $2-3$ m. Greater knee flexion $\left(103 \pm 9.4^{\circ}\right.$ versus $\left.113.83 \pm 5.9^{\circ}\right)$ was also observed at foot strike in the first stride. Such results are consistent with previous investigations of unresisted [23] and resisted sprinting [28] whereby velocity and stride length increase and joint range of motion may decrease with increased distance. 
Comparable stride rates $(1.42 \pm 0.14 \mathrm{~Hz}$ versus $1.45 \pm 0.50 \mathrm{~Hz})$ were seen in this study at $2-$ $3 \mathrm{~m}$ to that (at $2.5 \mathrm{~m}$ ) of Keogh and colleagues [3] in which six resistance-trained athletes performed three $25-\mathrm{m}$ heavy sled pull trials. Differences were apparent with athletes in the present study demonstrating greater average velocities $\left(1.83 \pm 0.22 \mathrm{~m}^{-1} \mathrm{~s}^{-1}\right.$ vs $1.04 \pm 0.30 \mathrm{~m} \cdot \mathrm{s}^{-}$ $\left.{ }^{1}\right)$, stride lengths $(1.29 \pm 0.17 \mathrm{~m}$ versus $0.74 \pm 0.28 \mathrm{~m})$, swing times $(0.33 \pm 0.04 \mathrm{~s}$ versus 0.25 $\pm 0.06 \mathrm{~s})$ and shorter ground contact times $(0.35 \pm 0.04 \mathrm{~s}$ versus $0.48 \pm 0.23 \mathrm{~s})$ than Keogh and colleagues [3]. Loading (70\%1RM squat versus an absolute load of $171.2 \mathrm{~kg}$ ), environmental factors (laboratory versus outdoors course), and strongman training experience and competition level, may explain the differences observed in these studies.

Relatively few significant differences were observed between the ground reaction forces of the first stride and stride at $2-3 \mathrm{~m}$ of the heavy sled pull. The first stride was associated with greater mean forces in the anterior-posterior $(526 \pm 162 \mathrm{~N}$ versus $271 \pm 89 \mathrm{~N})$ and mediallateral $(24 \pm 8 \mathrm{~N}$ versus $-5 \pm 22 \mathrm{~N})$ axis. The mean ratio of force $(\%)$ results were consistent with our initial hypothesis whereby significant differences $(\mathrm{p}<0.01)$ were evident between the first stride and stride at $2-3 \mathrm{~m}(37.4 \pm 3.8 \%$ versus $21.7 \pm 7.1 \%)$ of the heavy sled pull (respectively). Such differences may reflect the kinematics associated with these phases. The greater horizontal body position seen in the first stride (i.e. $125 \%$ greater trunk angle at foot strike) would allow for greater anterior-posterior propulsive forces to be applied than the more upright position associated with the stride at $2-3 \mathrm{~m}$. The mean ratio of forces for the heavy sled pull's first stride is comparable to those reported for the second step ground contact with sled towing with loads of $30 \%$ body mass $(\mathrm{RF}=39.0 \pm 1.6 \%)$ [19], but higher than those reported for unresisted sprinting $(\mathrm{RF}=28.0 \pm 1.6 \%)$ and sled towing with loads of $10 \%$ body mass $(\mathrm{RF}=31.4 \pm 0.6 \%)$ [19]. The results of this study and the studies of Kawamori and colleagues $[11,19]$ demonstrate that the heavy sled pulling with loads equal to 
or greater than $30 \%$ body mass may be an efficient training stimulus to teach athletes to produce ground reaction force more horizontally, which is an important factor to sprint acceleration performance $[18,29]$.

An interesting finding in this study was that observations of ground reaction force data showed reduced forces in all three axes for the heavy sled pull at $2-3 \mathrm{~m}$ compared to the first stride. Such results may be attributed to friction and the force-velocity relationship. While the present study used carpet attached underneath the sled on a linoleum floor, a greater force was required at the start of the sled pull to initiate movement to overcome the force of static friction [30]. Once this static frictional force was overcome, less force was needed to continue to move the sled as the coefficient of sliding friction was less than that of static friction [31]. Differences in the coefficient of friction $(0.21$ to $0.58 \mu)$ have been shown to make substantial differences in $30 \mathrm{~m}$ weighted sled $(55 \mathrm{~kg})$ towing times [32]. Coaches considering using heavy sled pull with their athletes need to pick training loads based on surface type, demands of the sport and what part of the force velocity curve they are trying to develop within their athletes.

\section{CONCLUSION}

The results of this study provide coaches with the first combined description of the heavy sled pull's kinetic and kinematic characteristics and how these compare to a common lower body exercise, the back squat. The heavy sled pull and squat force profiles show that these exercises are effective conditioning exercises to generate high propulsive and vertical forces (respectively). The heavy sled and squat may both have some advantages over each other as effective conditioning tools to develop different aspects of muscular performance. Coaches who wish to utilise the heavy sled pull in conditioning practice should be aware that load, 
training surface, sled, type and position of harness and length of chain may all influence sled pull kinematics and force-velocity characteristics. Coaches should consider individualised exercise prescription with a sports specific approach to elicit optimal neuromuscular adaptations. Future longitudinal training studies are needed to investigate the chronic effects of heavy sprint-style sled pulling on speed and player performance, especially those athletes in collision sports such as rugby or American football where higher levels of sprint momentum are needed to make and break tackles.

\section{ACKNOWLEDGEMENTS}

The authors would like to thank each of the strongman athletes who participated in this study and Anna Lorimer for her help with data collection. 


\section{REFERENCES}

1. Winwood, P.W., Keogh, J.W.L. and Harris, N.K., The Strength and Conditioning Practices of Strongman Competitors, Journal of Strength and Conditioning Research, 2011, 25(11), 3118-28.

2. Baker, D.G. and Newton, R.U., Comparison of Lower Body Strength, Power, Acceleration, Speed, Agility, and Sprint Momentum to Describe and Compare Playing Rank Among Professional Rugby League Players, Journal of Strength and Conditioning Research, 2008, 22(1), 153-8.

3. Keogh, J.W.L., Newlands, C., Blewett, S., Payne, A. and Chun-Er, L., A Kinematic Analysis of a Strongman Event: The Heavy Sprint-Style Sled Pull, Journal of Strength and Conditioning Research, 2010, 24(11), 3088-97.

4. Jakalski, K., The Pros and Cons of Using Resisted and Assisted Training Methods with High School Sprinters: Parachutes, Tubing and Towing, Track Coach, 1998, 144, 45859.

5. Winwood, P.W., Cronin, J.B., Dudson, M.K., Gill, N.D. and Keogh, J.W.L., How Coaches Use Strongman Implements in Strength and Conditioning Practice, International Journal of Sports Science \& Coaching, In Press.

6. Alcaraz, P.E., Palao, J.M. and Elvira, J.L.L., Determining the Optimal Load for Resisted Sprint Training with Sled Towing, Journal of Strength and Conditioning Research, 2009, 23(2), 480-5.

7. Rushall, S.B. and Pyke, S.F., Training for Sports and Fitness, South Yarra, MacMillian Publishers, 2001.

8. Lockie, R.G., Murphy, A.J. and Spinks, C.D., Effects of Resisted Sled Towing on Sprint Kinematics in Field-Sport Athletes, Journal of Strength and Conditioning Research, 2003, 17, 760-7.

9. Alcaraz, P.E., Palao, J.M., Elvira, J.L.L. and Linthorne, N.P., Effects of Three Types of Resisted Sprint Training Devices on the Kinematics of Sprinting at Maximum Velocity, Journal of Strength and Conditioning Research, 2008, 22(3), 890-7.

10. Maulder, P.S., Bradshaw, E.J. and Keogh, J., Jump Kinetic Determinants of Sprint Acceleration Performance from Starting Blocks in Male Sprinters, Journal of Sports Science and Medicine, 2006, 5, 359-66. 
11. Kawamori, N., Newton, R.U., Hori, N. and Nosaka, K., Effects of Weighted Sled Towing with Heavy Versus Light Load on Sprint Acceleration Ability, Journal of Strength \& Conditioning Research, In Press.

12. Harrison, A.J. and Bourke, G., The Effect of Resisted Sprint Training on Speed and Strength Performance in Male Rugby Players, Journal of Strength and Conditioning Research, 2009, 23(1), 275-83.

13. Winwood, P.W., Cronin, J.B., Brown, S.R. and Keogh, J.W.L., A Biomechanical Analysis of the Farmers Walk and Comparison with the Deadlift and Unloaded Walk, International Journal of Sports Science and Coaching, In Press.

14. Wilson, G., Strength and Power Assessment, Applied Anatomy and Biomechanics in Sport, Melbourne, Blackwell Scientific Publications, 1994.

15. Baker, D. and Nance, S., The Relation Between Running Speed and Measures of Strength and Power in Professional Rugby League Players, Journal of Strength and Conditioning Research, 1999, 13(3), 230-5.

16. Bowerman, E., Whatman, C., Harris, N. and Bradshaw, E., Reliability of 2D Lower Extremity Alignment Measures in Elite Adolescent Ballet Dancers, $\underline{\text { New Zealand Journal of }}$ Sports Medicine, 2013, 40(2), 70-3.

17. Keogh, J., Kattan, A., Logan, S., Bensley, J., Muller, C. and Powell, L., A Preliminary Kinematic Gait Analysis of a Strongman Event: The Farmers Walk, Sports, 2014, 2, 24-33. 18. Morin, J-B., Edouard, P., Samozino, P., Technical Ability of Force Application as a Determinant Factor of Sprint Performance, Medicine \& Science in Sports \& Exercise, 2011, 43(9), 1680-8.

19. Kawamori, N., Newton, R., Nosaka, K., Effects of Weighted Sled Towing on Ground Reaction Force During the Acceleration Phase of Sprint Running, Journal of Sports Sciences, 2014, 32(12), 1139-45.

20. Hunter, J.P., Marshall, R.N. and McNair, P.J., Interaction of Step Length and Step Rate During Sprint Running, Medicine \& Science in Sports \& Exercise, 2004, 36, 261-71. 21. Hunter, J.P., Marshall, R.N. and McNair, P.J., Relationships Between Ground Reaction Force Impulse and Kinematics of Sprint Running Acceleration, Journal of Applied Biomechanics, 2005, 21, 31-43.

22. Weyand, P.G., Sternlight, D.B., Bellizzi, M.J. and Wright, S., Faster Top Running Speeds are Achieved With Greater Ground Forces Not More Rapid Leg Movements, Journal of Applied Physiology, 2000, 89(5), 1991-2000. 
23. Brughelli, M., Cronin, J. and Chaouachi, A., Effects of Running Velocity on Running Kinetics and Kinematics, Journal of Strength and Conditioning Research, 2011, 25(4), 933-9.

24. Kawamori, N., Nosaka, K. and Newton, R.U., Relationships Between Ground Reaction Impulse and Sprint Acceleration Performance in Team Sport Athletes, Journal of Strength \& Conditioning Research, 2013, 27(3), 568-73.

25. Cottle, C., Carlson, L.A. and Lawrence, M.A., Effects of Sled Towing on Sprint Starts, Journal of Strength \& Conditioning Research, In Press.

26. Swinton, P.A., Lloyd, R., Keogh, J.W.L., Agouris, I. and Stewart, A.D., A Biomechanical Comparison of the Traditional Squat, Powerlifting Squat, and Box Squat, Journal of Strength \& Conditioning Research, 2012, 26(7), 1805-16.

27. Bloomquist, K., Langberg, H., Karlsen, S., Madsgaard, S., Boesen, M., Raastad, T., Effect of Range of Motion in Heavy Load Squatting on Muscle and Tendon Adaptations, European Journal of Applied Physiology, 2013, 113, 2133-42.

28. Cronin, J., Hansen, K., Kawamori, N. and McNair, P., Effects of Weighted Vests and Sled Towing on Sprint Kinematics, Sports Biomechanics, 2008, 7(2), 160-72.

29. Kugler, F. and Janshen, L., Body Position Determines Propulsive Forces in Accelerated Running, Journal of Biomechanics, 2010, 43, 343-8.

30. Ozkaya, N. and Nordin, M., Fundamentals of Biomechanics: Equilibrium Motion and Deformation, New York, Springer, 1999.

31. Baechle, T.R. and Earle, R.W., Essentials of Strength Training and Conditioning: National Strength and Conditioning Association, 3rd ed, Champaign, IL, Human Kinetics, 2008 .

32. Linthorne, N.P. and Cooper, J.E., Effect of the Coefficient of Friction of a Running Surface on Sprint time in a Sled-Towing Exercise, Sports Biomechanics, 2013, 12(2), 17585. 


\section{Figure Legends}

Figure 1: Carpet Attached to the Sled to Prevent Damage to the Linoleum Floor.................31

Figure 2: Sony Camera and Force Platform Set Up ....................................................... 32

Figure 3: Pictorial Representation of the Four Angles Measured at Start of Concentric (SC), and at Maximal Knee Extension (MKE) (From Left to Right) in the Squat (Top Row) and Heavy Sled Pull (Bottom Row)

Figure 4: Schematic Representation of the Joint Angles Calculated (Adapted From Keogh et al. 2010)

Figure 5: Group Mean Vertical (Top), Anterior/Posterior (Middle) and Medial/Lateral (Bottom) Force-Time Curves (Normalised to Percentage of Mean Lift Time) Obtained With a 70\% 1-Repetition Maximum Load for the Squat and Sled pull (From the Start of the Concentric Phase to the Point of Maximal Knee Extension) .35

Figure 6: Group Mean Vertical (Top), Anterior/Posterior (Middle) and Medial/Lateral (Bottom) Force-Time Curves (Normalised to Percentage of Mean Lift Time) for the Sled Pull Conditions (First Stride and Stride at 2 -3m) Obtained With a 70\% 1-Repetition Squat load.

\section{Table Legends}

Table 1: Demographics, Training Characteristics and Strength Measures (mean \pm SD) for Strongman Athletes.

Table 2: Kinematics of Trunk, Hip, Knee and Ankle Angles Performed from the Start of the Concentric Phase to the Point of Maximal Knee Extension for the Squat and Sled Pull (From a Bilateral Plate Start)

Table 3: Kinetic Characteristics of Ground Reaction Force for the Squat and Heavy SprintStyle Sled Pull (From the Bilateral Start of the Concentric Phase (SC) to the Point of

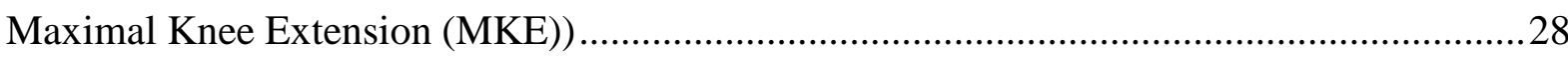

Table 4: Differences in Gait Kinematics Between the Heavy Sled Pull Conditions

Table 5: Kinetic Characteristics of Ground Reaction Force for the Heavy Sled Pull First

Stride and Heavy Sled Pull Stride at 2 - 3 m 30 
Table 1: Demographics, Training Characteristics and Strength Measures (mean \pm SD) for Strongman Athletes

All Strongman athletes

$(\mathrm{n}=6)$

\section{Demographics}

Age (y)

$24.0 \pm 3.9$

Height $(\mathrm{cm})$

$181.6 \pm 9.4$

Body mass $(\mathrm{kg})$

$112.9 \pm 28.9$

\section{Training}

Resistance training experience (y)

$6.5 \pm 2.7$

Strongman implement training experience (y)

$2.7 \pm 1.6$

Number of resistance training sessions per week

$4.2 \pm 1.2$

Average time of resistance training session (min) $\quad 90.8 \pm 30.4$

Strength (1RM)

Squat $(\mathrm{kg})$

$210.0 \pm 59.1$

Squat $\left(\mathrm{kg} k g^{-1}\right)$

$1.87 \pm 0.28$ 
Table 2: Kinematics of Trunk, Hip, Knee and Ankle Angles Performed from the Start of the Concentric Phase to the Point of Maximal Knee Extension for the Squat and Sled Pull (From a Bilateral Plate Start)

$\begin{array}{ll}\begin{array}{l}\text { Squat } \\ \text { (SC to MKE) }\end{array} & \begin{array}{l}\text { Sled pull } \\ \text { (SC to MKE) }\end{array} \\ 38.8 \pm 5.2^{\dagger} & 101.4 \pm 5.7 \\ 57.0 \pm 9.7 & 65.6 \pm 12.6 \\ 62.6 \pm 6.3^{\dagger 0.007} & 95.8 \pm 18.5 \\ 81.0 \pm 7.3 & 76.0 \pm 7.3\end{array}$

Ankle angle $\left({ }^{\circ}\right)$

Maximum knee Extension (MKE)

Trunk angle $\left({ }^{\circ}\right)$

$10.0 \pm 4.3^{\dagger 0.007}$

$81.2 \pm 20.0$

Hip angle $\left({ }^{\circ}\right)$

$163.0 \pm 5.5^{\dagger 0.006}$

$117.4 \pm 11.0$

Knee angle $\left({ }^{\circ}\right)$

$167.4 \pm 4.6^{\dagger 0.01}$

$133.2 \pm 10.1$

Ankle angle $\left(^{\circ}\right)$

$105.0 \pm 3.9$

$107.8 \pm 7.2$

Range of Motion (ROM)

Trunk angle $\left({ }^{\circ}\right)$

$$
-28.8 \pm 5.1
$$

$-20.2 \pm 19.7$

Hip angle $\left({ }^{\circ}\right)$

$106.0 \pm 9.3^{\dagger 0.002}$

$51.8 \pm 19.0$

Knee angle $\left({ }^{\circ}\right)$

$104.8 \pm 9.8^{\dagger 0.004}$

$37.4 \pm 14.7$

Ankle angle $\left({ }^{\circ}\right)$

$24.0 \pm 6.1$

$31.8 \pm 9.4$

Data expressed as mean $\pm \mathrm{SD}$.

$\dagger$ significantly different to other level of variable $\mathrm{p}=<0.001$ unless specified. 
Table 3: Kinetic Characteristics of Ground Reaction Force for the Squat and Heavy SprintStyle Sled Pull (From the Bilateral Start of the Concentric Phase (SC) to the Point of Maximal Knee Extension (MKE))

\begin{tabular}{lll}
\hline & $\begin{array}{l}\text { Squat } \\
(\text { SC to MKE) }\end{array}$ & $\begin{array}{l}\text { Heavy Sled Pull } \\
\text { (SC to MKE) }\end{array}$ \\
\hline Z axis & $3503 \pm 1268^{\dagger 0.005}$ & $1736 \pm 463$ \\
\hline Peak vertical force (N) & $2579 \pm 648^{\dagger}$ & $1326 \pm 364$ \\
Mean vertical force (N) & $126 \pm 73^{\dagger}$ & $810 \pm 174$ \\
\hline Y axis & $43 \pm 22^{\dagger}$ & $555 \pm 107$ \\
\hline Peak anterior force (N & $-133 \pm 79$ & $-53 \pm 48$ \\
Mean anterior force (N) & $-35 \pm 13$ & $-32 \pm 24$ \\
Peak posterior force (N) & $-8 \pm 10^{\dagger}$ & $522 \pm 110$ \\
Mean posterior force (N) & $89 \pm 44$ & $156 \pm 72$ \\
Mean of Y forces (Fh) (N) & $19 \pm 9$ & $72 \pm 47$ \\
\hline X axis & $-90 \pm 55$ & $-94 \pm 57$ \\
\hline Peak medial force (N) & $-23 \pm 15$ & $-53 \pm 35$ \\
Mean medial force (N) & $-3 \pm 8$ & $3 \pm 52$ \\
Peak lateral force (N) & $2579 \pm 649^{\dagger}$ & $1440 \pm 368$ \\
Mean lateral force (N) & $0.2 \pm 0.3^{\dagger}$ & $39.3 \pm 5.9$ \\
Mean of X forces (N) & & \\
\hline Total resultant ground reaction force (Ftot) (N) & & \\
Mean ratio of forces applied onto the ground (\%) & & \\
\hline Data expressed as $\mathrm{N}$ (N) & & \\
\hline
\end{tabular}

Data expressed as mean \pm SD.

$\dagger$ Significantly different to other level of variable $p<0.001$ unless specified 
Table 4: Differences in Gait Kinematics Between the Heavy Sled Pull Conditions

\begin{tabular}{|c|c|c|}
\hline & $\begin{array}{l}\text { Sled Pull } \\
\text { (1st Stride) }\end{array}$ & $\begin{array}{l}\text { Sled Pull } \\
\text { (Stride at } 2-3 \mathrm{~m} \text { ) }\end{array}$ \\
\hline Average velocity $\left(\mathrm{m} \cdot \mathrm{s}^{-1}\right)$ & $1.39 \pm 0.13^{\dagger 0.049}$ & $1.83 \pm 0.22$ \\
\hline Stride length (m) & $1.00 \pm 0.15^{\dagger 0.01}$ & $1.29 \pm 0.17$ \\
\hline Stride rate $(\mathrm{Hz})$ & $1.41 \pm 0.14$ & $1.42 \pm 0.14$ \\
\hline Ground contact time (s) & $0.38 \pm 0.03$ & $0.35 \pm 0.04$ \\
\hline Swing time (s) & $0.31 \pm 0.06$ & $0.33 \pm 0.04$ \\
\hline \multicolumn{3}{|l|}{ Foot Strike (FS) } \\
\hline Trunk angle $\left(^{\circ}\right)$ & $76.8 \pm 30.4$ & $61.17 \pm 13.4$ \\
\hline Hip angle $\left(^{\circ}\right)$ & $81.2 \pm 30.4$ & $91.00 \pm 16.2$ \\
\hline Knee angle $\left({ }^{\circ}\right)$ & $103.0 \pm 9.4^{\dagger 0.005}$ & $113.83 \pm 5.9$ \\
\hline Ankle angle $\left({ }^{\circ}\right)$ & $90.6 \pm 7.2$ & $84.50 \pm 2.1$ \\
\hline \multicolumn{3}{|l|}{ Toe Off $(T O)$} \\
\hline Trunk angle $\left({ }^{\circ}\right)$ & $68.8 \pm 20.2$ & $60.83 \pm 10.7$ \\
\hline Hip angle $\left(^{\circ}\right)$ & $127.2 \pm 20.0$ & $133.83 \pm 18.4$ \\
\hline Knee angle $\left({ }^{\circ}\right)$ & $132.8 \pm 14.5$ & $137.83 \pm 14.0$ \\
\hline Ankle angle $\left(^{\circ}\right)$ & $126.6 \pm 19.1$ & $123.33 \pm 14.9$ \\
\hline \multicolumn{3}{|l|}{ Range of Motion (ROM) } \\
\hline Trunk angle $\left({ }^{\circ}\right)$ & $-8.0 \pm 11.5$ & $-0.33 \pm 8.1$ \\
\hline Hip angle $\left({ }^{\circ}\right)$ & $46.0 \pm 25.9$ & $42.83 \pm 13.2$ \\
\hline Knee angle $\left(^{\circ}\right)$ & $29.8 \pm 16.0$ & $24.00 \pm 11.0$ \\
\hline Ankle angle $\left({ }^{\circ}\right)$ & $36.0 \pm 18.8$ & $38.83 \pm 14.3$ \\
\hline
\end{tabular}

Data expressed as mean \pm SD.

$\dagger$ significantly different to other level of variable $(\mathrm{p}<0.05)$ 
Table 5: Kinetic Characteristics of Ground Reaction Force for the Heavy Sled Pull First Stride and Heavy Sled Pull Stride at 2 - 3 m

$\begin{array}{ll}\text { Heavy Sled Pull } & \text { Heavy Sled Pull } \\ \text { (First stride) } & \text { (Stride at } 2-3 \mathrm{~m} \text { ) }\end{array}$

\begin{tabular}{|c|c|c|}
\hline Z axis & & \\
\hline Peak vertical force $(\mathrm{N})$ & $2154 \pm 1054$ & $1821 \pm 424$ \\
\hline Mean vertical force $(\mathrm{N})$ & $1301 \pm 348$ & $1269 \pm 314$ \\
\hline \multicolumn{3}{|l|}{ Y axis } \\
\hline Peak anterior force $(\mathrm{N}$ & $1044 \pm 461$ & $768 \pm 170$ \\
\hline Mean anterior force $(\mathrm{N})$ & $543 \pm 166$ & $453 \pm 104$ \\
\hline Peak posterior force $(\mathrm{N})$ & $-627 \pm 609$ & $-511 \pm 436$ \\
\hline Mean posterior force $(\mathrm{N})$ & $-240 \pm 192$ & $-183 \pm 180$ \\
\hline Mean of $Y$ forces $(F h)(N)$ & $526 \pm 162^{\dagger 0.029}$ & $271 \pm 89$ \\
\hline \multicolumn{3}{|l|}{$\mathrm{X}$ axis } \\
\hline Peak medial force $(\mathrm{N})$ & $380 \pm 216$ & $247 \pm 102$ \\
\hline Mean medial force $(\mathrm{N})$ & $110 \pm 43$ & $83 \pm 43$ \\
\hline Peak lateral force $(\mathrm{N})$ & $-309 \pm 167$ & $-224 \pm 89$ \\
\hline Mean lateral force $(\mathrm{N})$ & $-97 \pm 58$ & $-89 \pm 44$ \\
\hline Mean of $X$ forces $(\mathrm{N})$ & $24 \pm 8^{\dagger 0.007}$ & $-5 \pm 22$ \\
\hline Total resultant ground reaction force (Ftot) $(\mathrm{N})$ & $1405 \pm 379$ & $1301 \pm 310$ \\
\hline Mean ratio of forces applied onto the ground (\%) & $37.4 \pm 3.8^{\dagger 0.009}$ & $21.7 \pm 7.1$ \\
\hline
\end{tabular}

Data expressed as mean \pm SD.

$\dagger$ Significantly different to other level of variable $\mathrm{p}<0.001$ unless specified 


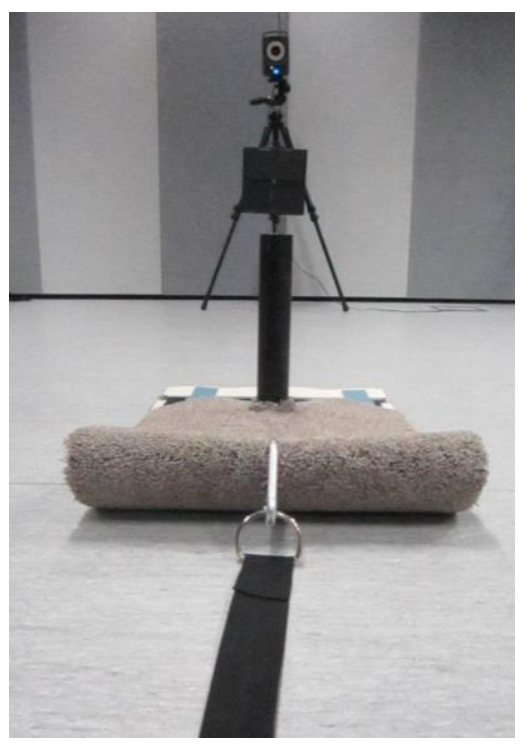

Figure 1: Carpet Attached to the Sled to Prevent Damage to the Linoleum Floor 


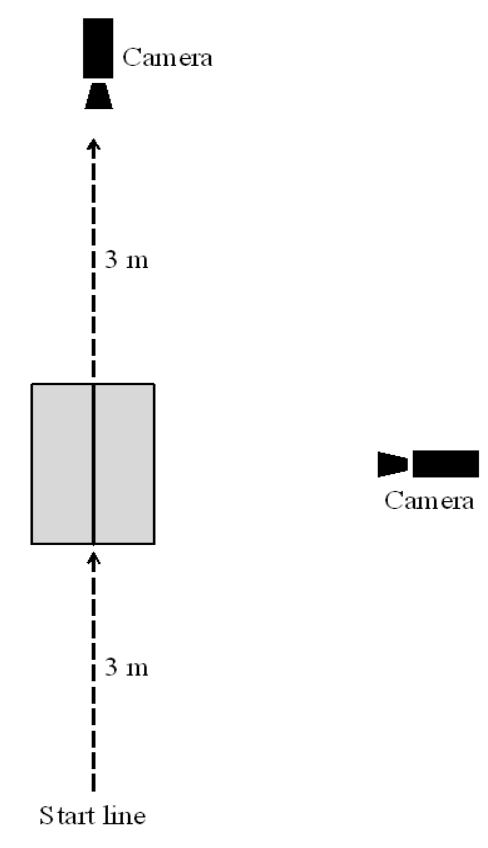

Figure 2: Sony Camera and Force Platform Set Up 


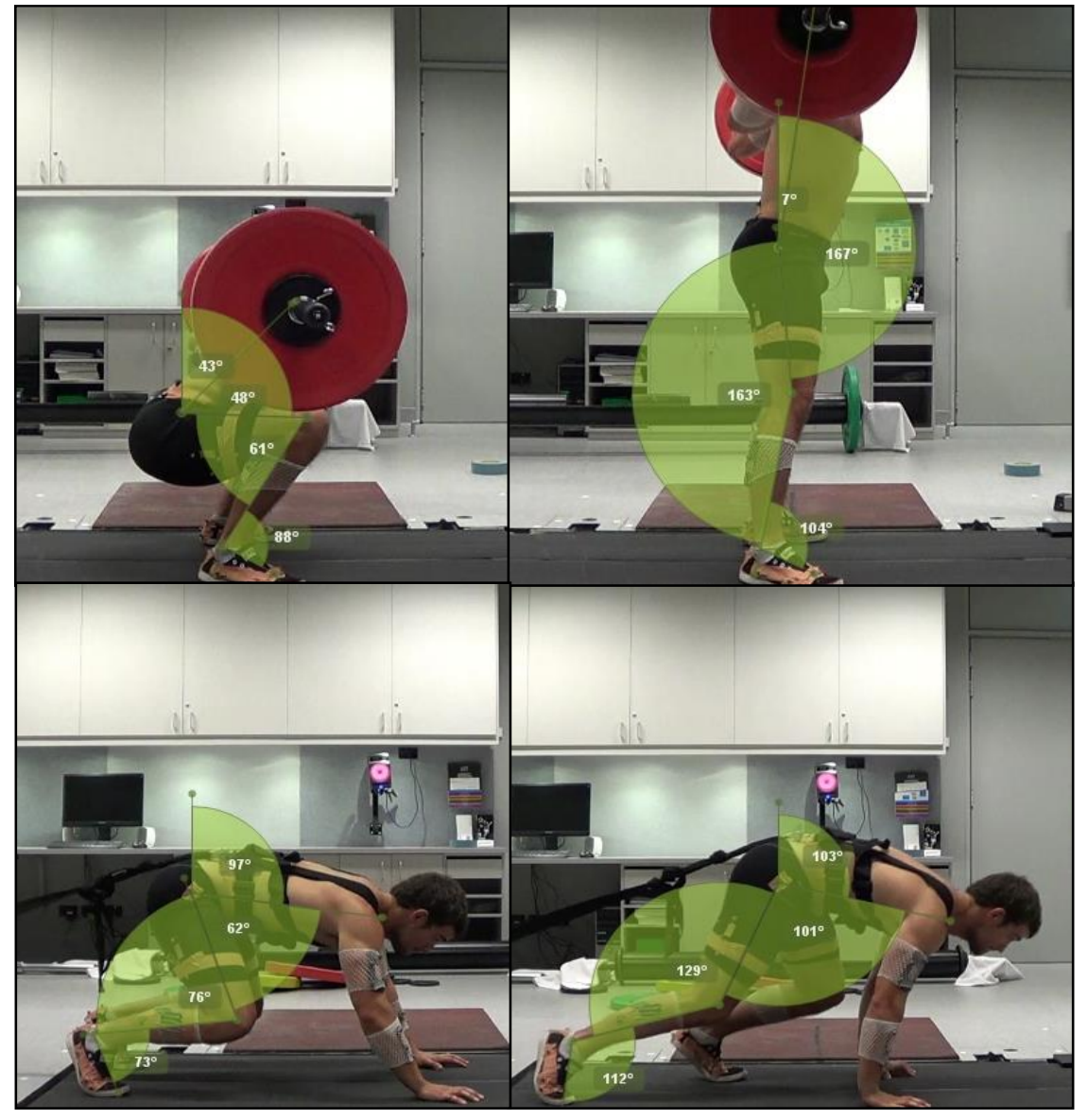

Figure 3: Pictorial Representation of the Four Angles Measured at Start of Concentric (SC), and at Maximal Knee Extension (MKE) (From Left to Right) in the Squat (Top Row) and Heavy Sled Pull (Bottom Row) 


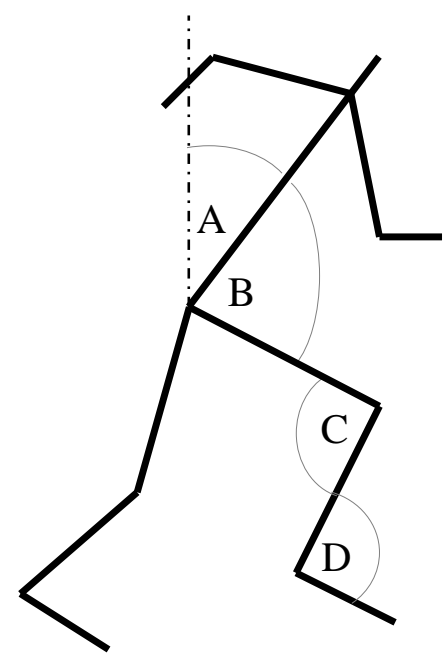

Figure 4: Schematic Representation of the Joint Angles Calculated (Adapted From Keogh et al. 2010) 

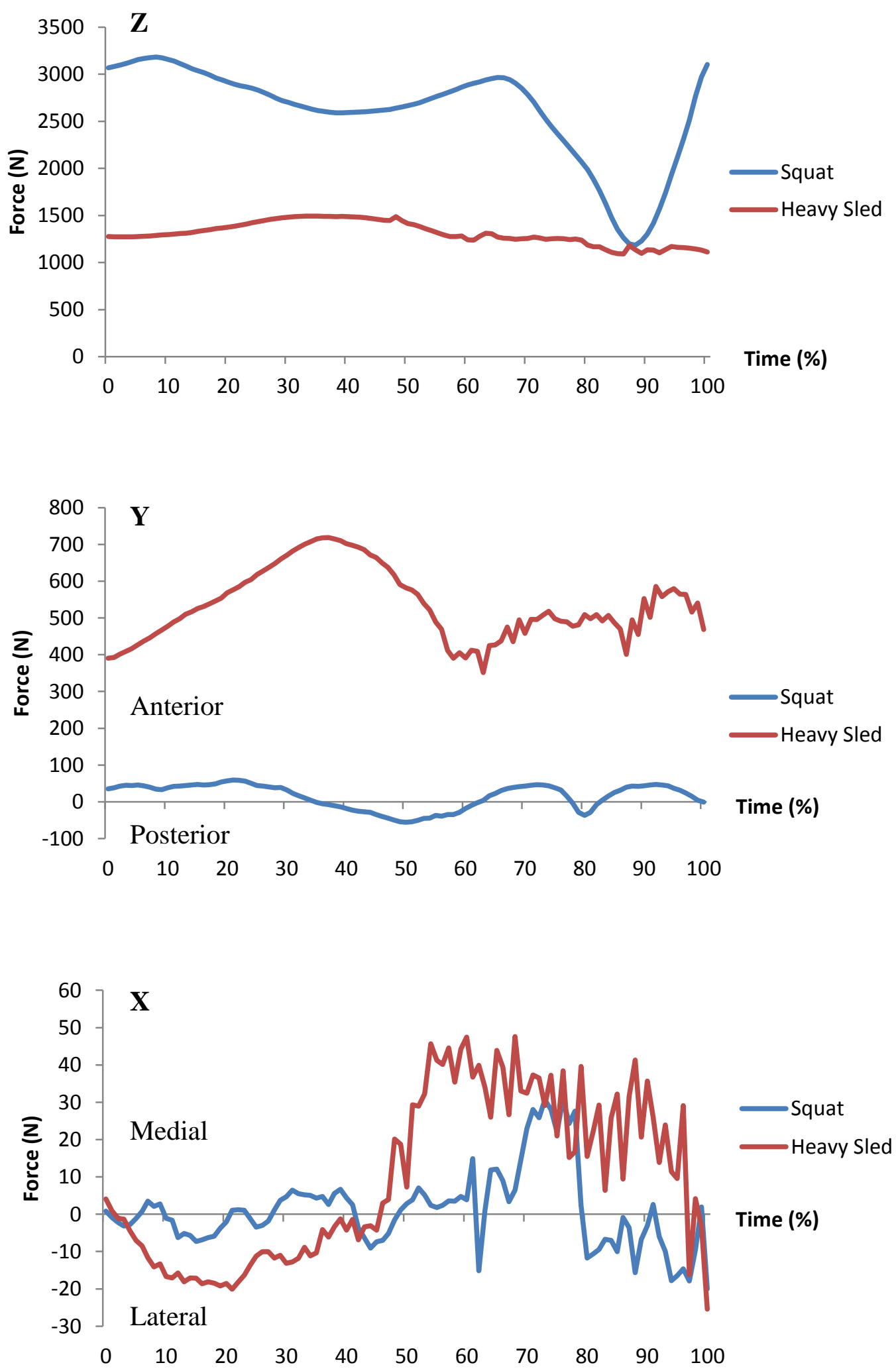

Figure 5: Group Mean Vertical (Top), Anterior/Posterior (Middle) and Medial/Lateral (Bottom) Force-Time Curves (Normalised to Percentage of Mean Lift Time) Obtained With a 70\% 1-Repetition Maximum Load for the Squat and Sled pull (From the Start of the Concentric Phase to the Point of Maximal Knee Extension) 

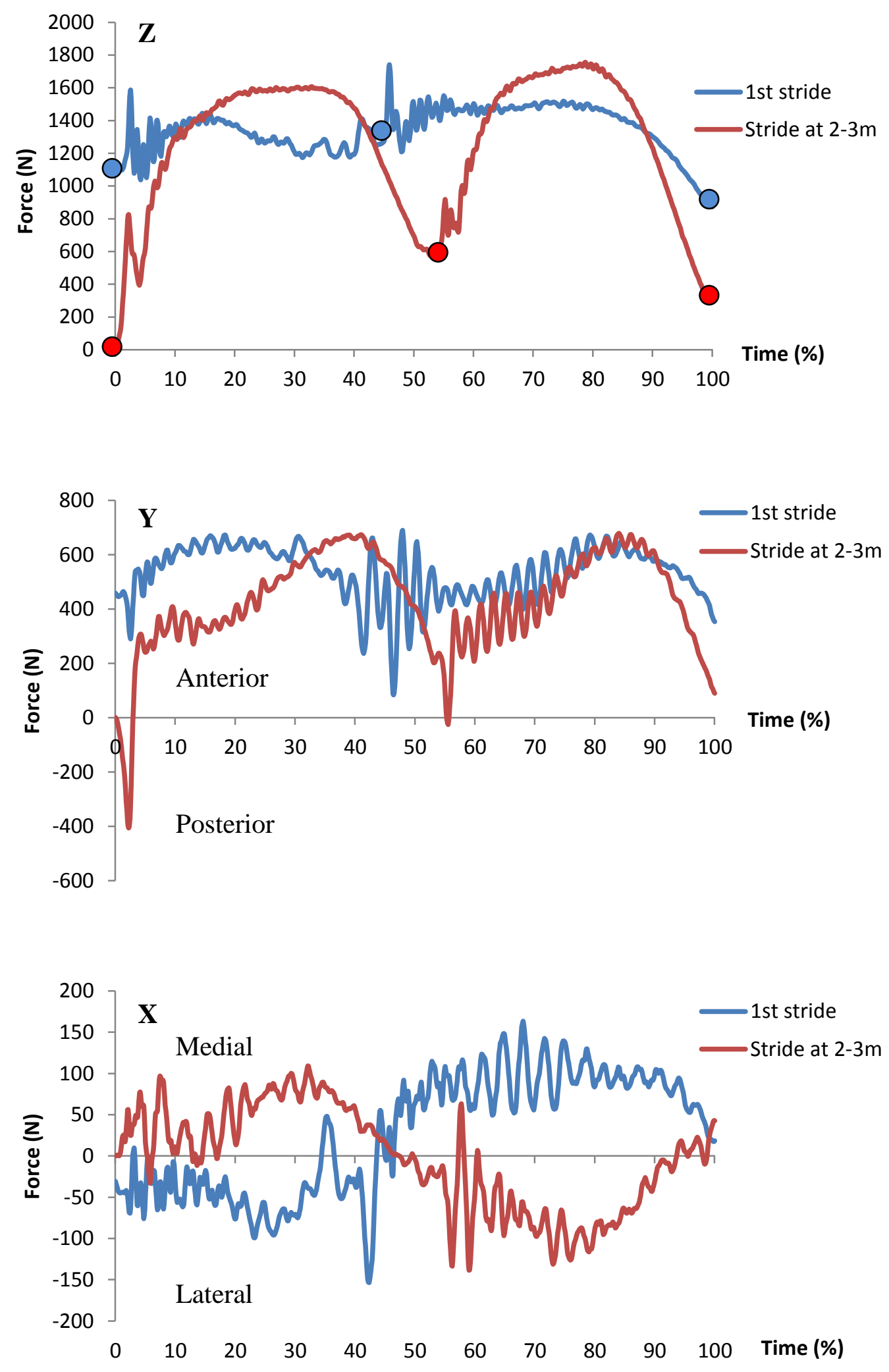

Figure 6: Group Mean Vertical (Top), Anterior/Posterior (Middle) and Medial/Lateral (Bottom) Force-Time Curves (Normalised to Percentage of Mean Lift Time) for the Sled Pull Conditions (First Stride and Stride at $2-3 \mathrm{~m}$ ) Obtained With a 70\% 1-Repetition Squat load. Circles Indicate Left or Right Foot Strikes in the Sled Pull Conditions 